\title{
Readiness For Shifting From A Traditional Higher Education Learning System To An E-Learning System: A Case Study From The Sultanate Of Oman
}

Said Al-Gattoufi, (E-mail: Gattoufi@squ.edu.om), Sultan Qaboos University, Sultanate of Oman Salem Al-Naabi, (E-mail: abuhamada@ hotmail.com), Nizwa College of Applied Sciences, Sultanate of Oman Béchir Gattoufi, (E-mail: bgattoufi@gmail.com), Nizwa College of Applied Sciences, Sultanate of Oman

\begin{abstract}
The Ministry of Higher Education in the Sultanate of Oman initiated recently a restructuring program for the General Directorate Colleges of Education aiming to replace the existing six colleges with more applied and highly IT assisted institutions. A particular emphasis is directed towards improving the learning methods by developing and implementing a unified Learning Management System (LMS), which will serve the new form of these colleges. Such system is particularly intended to improve the e-learning skills in the six Colleges of Education. Each college has a Learning Resource Center (LRC) that provides IT services for about 1500 students and 150 staff members. During the past few years, the LRC at Nizwa College of Education (NCoE) has exerted many efforts in upgrading such services to the benefit of the college community. The discussion in this paper will be based on Nizwa LRC as an example, reflecting uniformity among the six colleges of education. This paper analyzes the readiness of the current learning system for the gradual shifting to a more IT assisted teaching system. First, the paper describes the evolution of the Intranet and Internet services in the college. Second, the steps realized in expanding and upgrading IT are described. Third, an evaluation of the available services and users is presented. This is supported by the analysis of the experimental implementation of an open source LMS, the "Modular Object-Oriented Dynamic Learning Environment" (Moodle) to assess the effectiveness of Moodle as a learning facilitator. Finally, recommendations on how to improve the outsourcing of these services are given. Aspects of the services provided by the LRC will be discussed through different users' perspectives.
\end{abstract}

\section{MODERN E-LEARNING TOOLS AVAILABLE ON THE WEB}

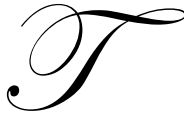

he internet service is progressing from a medium environment with Web 1.0 to Web 2.0 as a platform. Many important tools marked this evolution, such as Blogs, Bloglines, Wikis, Podcasts, Ajax and Rich Internet Applications (RIA). All of these tools offer internet services which are free, quick and user-friendly.

Rich Internet Applications (RIA) are web applications that have the features and functionality of traditional desktop applications. RIAs typically transfer the processing necessary for the user interface to the web client, but keep the bulk of the data (i.e. maintaining the state of the program, the data etc) back on the application server. RIA are characterized typically by running in a web browser and do not require software installation, running locally in a secure environment called a sandbox and having the possibility to be "occasionally connected" wandering in and out of hot-spots or from office to office. A list of rich Internet applications can be organised by their uses such as Communication (Gmail, Meebo, Outlook Web Access, Yahoo Mail and Windows Live Hotmail), Document managing, editing, sharing and collaborating (EditGrid, Flickr, FORscene, Google Docs \& Spreadsheets, Wrike, 
Zoho Office Suite and Cyclone3 XULadmin) and Personal information management (30 Boxes, Google Calendar, Netvibes and Windows Live Favourites).

Two learning management systems (LMS) namely Blackboard (merged with WebCT) and the Modular Object-Oriented Dynamic Learning Environment (Moodle) will be in focus. Blackboard is "an e-Education platform designed to enable educational innovations everywhere by connecting people and technology."[6] Moodle is an open source. "It is a course management system designed to help educators who want to create quality online courses. The software is used all over the world by universities, schools, companies and independent teachers."[7] With Moodle you can build an electronic classroom, which allows the classroom to be extended onto the web. This program allows a common place for students to go for many classroom resources. When using any LMS, you can for instance post news items, assign and collect assignments, or post electronic journals and resources, and more.

\section{STEPS DONE FOR SHIFTING TO E-LEARNING USES IN NIZWA COLLEGE}

Since the Intranet and Internet services were introduced at Nizwa College of Education in 1998, the need to examine the use of the facility by the academic community has been strongly felt. This need became particularly pressing as the dramatic increase in Intranet and Internet usage was witnessed. In addition, the results of the study are expected to be useful in planning the future development and enhancement of the facility in the Learning Resource Center at Nizwa College of Education.

In May 1998, a complete Local Area Network (LAN) installation was accomplished linking more than 100 computers and a proportional number of peripherals like printers and scanners. During the following years more installations have been taking place. LAN access was provided to all college buildings for almost every staff office. More computers and peripherals were installed. A lot of these have been also upgraded. Nowadays, the total number of computers inside the college has reached around 600. These computers are distributed in 8 computer labs, one media lab, and different staff and faculty offices.

The internet service, which was initially introduced to the college in September 1998, had 2 dialup lines which were used to connect various college computers within the campus. The number of dialup lines was increased in the subsequent 4 years to a total of 6 lines. The actual dialup line speed is not more than $40 \mathrm{Kbps}$ and, because of the huge amount of traffic for each line, traffic jams occurred very frequently and needed to be addressed.

In 2004, the college administration agreed to financially support a bigger bandwidth. Since these are very expensive in Oman, a $256 \mathrm{Kbps}$ Internet Leased Line (ILL) was installed in December 2004. The ambition to clear off all traffic jams was not completely fulfilled. The tendency to use the internet has increased with the introduction of the ILL and jams kept reoccurring during peak time. Higher bandwidth for Internet connectivity has always been the goal of the LRC and tremendous efforts were made to upgrade the ILL. For financial reasons, this never took place until February 2006 when 1024 Kbps bandwidth was put on.

In April 2006, wireless connectivity within the LRC building was introduced to the existing network, providing a versatile connectivity solution for those who are very mobile and yet require to be connected.

To boost the e-learning in and outside campus another efficient service is offered to the college researcher, which is the subscription to the EBSCO e-journals since the beginning of the academic year 2006/07. A complete access to the e-journals database is provided to faculty members and students to help them enrich their knowledge and understanding of the current issues in their field.

\section{E-LEARNING SERVICES AT NIZWA COLLEGE OF EDUCATION}

The infrastructural aspects, pedagogical considerations and the need to acknowledge the usefulness of technology are combined to enhance the learning experience at Nizwa College of Education. Two kinds of elearning activities have been developed:- 
The first one is local development. Everybody knows that the first important step in beginning an elearning activity is to encourage each teacher to develop his courseware. Therefore, each teacher can have a special folder on the Intranet server, where he can store his materials. Students can have a read-only copy of these files in class or at any time they have access to the intranet. A second special folder is allocated to the teacher. For this folder a read and write permission are allowed to students so they can store their assignments, projects, feedback and exams. The teacher has to transfer these files to the first folder to avoid any new change. A common sharing folder has been created on the intranet server where teachers' intranet websites are stored. Many e-books, software utilities and different kinds of materials can also be accessed.

The second activity is developed in collaboration with Sultan Qaboos University (SQU) in Muscat. All the computer teachers are invited to attend two CISCO courses on "HP IT essentials 1 and 2". Materials' courses are available on the CISCO website as distance learning, and exams are organized by the IT department at SQU. In the other way, some chosen teachers are allowed to have a WebCT ID, so they can use the WebCT/MOODLE installed on the same server at SQU.

A study about IT services provided by the LRC [1] has brought forward some important findings that deserve the attention of Nizwa College's Administration. Three surveys were conducted in order to fully understand the IT quality of many services offered in the NCoE by the LRC. Users of these services are classified into three categories: students, teachers and staff. Six ratings were given for each question to describe the opinion of users: very poor, poor, fair, good, very good and excellent. Questions are grouped in six fields: computer hardware, computer software, peripherals, intranet, internet and other LRC Services. The opinion of users about these fields is very important to enhance the quality of the IT environment and e-learning uses at NCoE. This should help students, teachers and staff members to move from the traditional concept of learning to the modern digital world of elearning. All staff members seemed very satisfied by the quality of the LRC services. Likewise, teachers were satisfied except for the availability of computer software. We recommended to the officials in the Ministry of Higher Education to revise the procedure of computer software procurement so that it becomes better-organized, much easier, and much more useful. The study has clearly demonstrated the non-satisfaction of students for the accessibility to computer software and hardware especially to printers. This is because of the lack of sufficient number of computer equipment. The Administration should have further attention to cope with this increasing demand for IT usage. This applies also to the "Internet". More action should be taken towards increasing the internet's bandwidth.

\section{USING MOODLE IN NIZWA COLLEGE}

Learning Management System (LMS) provide a service for teachers and students who increasingly look to the internet as the natural medium for finding information and resources. Since September 2006, Moodle has been installed on Nizwa College's server. Many round tables are organized between colleagues to encourage the use of Moodle as facilitator in teaching. The main problem of this installation is the non connectivity to the internet, so using Moodle is still limited to the campus. It will be resolved after the installation of a security firewall. A case study [2] has been done to establish whether Moodle is a facilitator of e-learning. We used it during this academic year in the teaching of two courses: "Foundation of Digital Technology Networking" during this semester and "Information Technology in the Digital World" during the first semester of this academic year 2006/2007. In the first year of the BSc in the College of Applied Sciences students attended a first year called "Foundation year" where they studied essentially English language and Computer Skills. A diagnosis of e-learning skills was done by focusing on the use of Moodle. The results of the questionnaire gave encouragement to use Moodle as a facilitator of e-learning free of charge. Its open source characteristics give a solid argumentation to go ahead, especially if it is compared with the extremely high price of other commercial LMS like Blackboard. A recommendation was put forward to the Administration for the use of Moodle. At the end of this semester, the assertion was made that Moodle can be a great learning facilitator. 


\section{READINESS TO IMPLEMENT BLACKBOARD IN NIZWA COLLEGE}

Since February 2007, only the IT Staff members are allowed to access the Blackboard website. All the materials that were needed were downloaded. The speed of the internet connection at the College is very low, so a helpful tools "Backpack" was used, that permits the surfing of Blackboard courses off-line. Blackboard has now been adopted by the Ministry of Higher Education and will be implemented by the beginning of the next academic year 2007/2008.

Readiness to implement a LMS needs a good preparation of the accessibility, information and IT skills agendas. "We are constantly making the mistake of specifying the means of doing something rather than the results we want. This can only limit our ability to find better solutions to real problems." (Gilb, 1988) In most cases, responding to current need is perhaps something done intuitively and without formal procedures. Implementing a new LMS or changing an existing teaching approach is likely to feel daunting, time-consuming and risky, especially when technology is involved. These risks and concerns are likely to be significantly diminished if a more explicit approach is taken to evaluating needs. There is certainly the usual need to justify limited time available and to be aware of likely technical requirements.

\section{STRENGTHS WEAKNESSES OPPORTUNITIES THREATS (SWOT) TABLE}

\begin{tabular}{|c|c|}
\hline 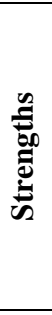 & $\begin{array}{ll}\text { - } & \text { Possibility of more interaction than with a lecture } \\
\text { - } & \text { Visualization (graphics, animation) better } \\
\text { - } & \text { 'Individual' attention is possible (although not personalized) } \\
\text { - } & \text { Self-paced (but limited if part of a conventional course) } \\
\text { - } & \text { Allows for different level of user } \\
\text { - } & \text { Consistency } \\
\text { - } & \text { Cheap (but only if it has a long technology/content 'lifetime') } \\
\text { - } & \text { Frees staff for more effective face-to-face work than mass lecturing } \\
\end{array}$ \\
\hline 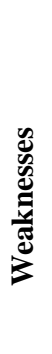 & 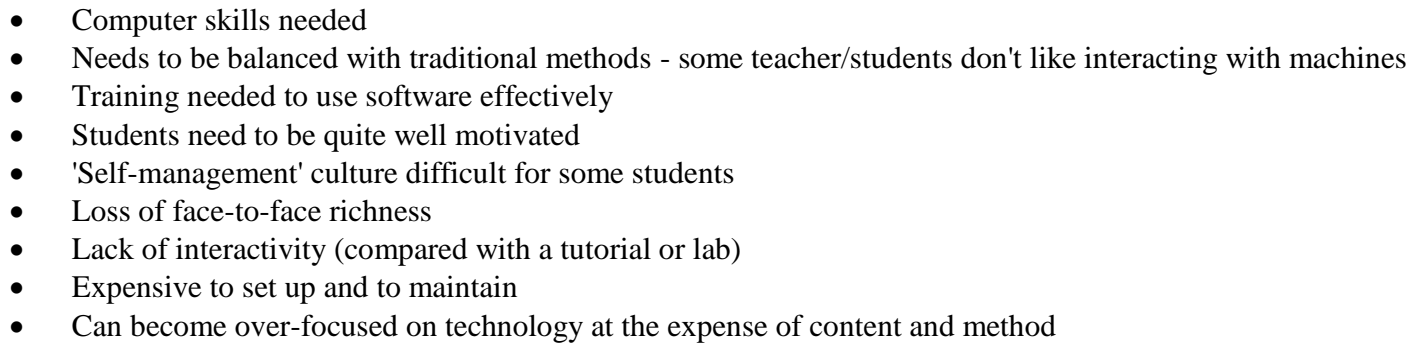 \\
\hline 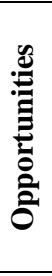 & $\begin{array}{ll}\text { - } & \text { More flexible access to learning } \\
\text { - } & \text { Can deal/reach more students over a range of times and locations } \\
\text { - } & \text { Better quality } \\
\text { - } & \text { May enable more choice of content } \\
\text { - } & \text { May be more democratic/egalitarian } \\
\text { - } & \text { Education can be tailored (Just in time/Just enough/Just for you) } \\
\text { - } & \text { Can be shared between Universities over the world (Oman/New Zeeland) }\end{array}$ \\
\hline 总 & $\begin{array}{ll}\text { - } & \text { Administration (mistakenly?) believes it is cheap } \\
\text { - } & \text { Job losses } \\
\text { - } & \text { Learning 'facts' may overshadow learning 'experience' } \\
\text { - } & \text { May turn higher education into a 'learning supermarket' } \\
\text { - } & \text { Less opportunity to ask the lecturer questions } \\
\text { - } & \text { Move away from traditional university values } \\
\end{array}$ \\
\hline
\end{tabular}


SWOT stands for 'Strengths Weaknesses Opportunities Threats'. It is a standard brainstorming and communication technique used to identify issues associated with change. An example of this exercise is given in the table below analyzing the broad benefits and constraints of implementing a LMS. [4] The next step in this process it should be the study in depth of each point listed in the following table.

\section{CONCLUSION}

Although the implementation of Moodle at Nizwa College of Applied Sciences was short and limited experience-which does not allow any specific generalizations to be safely made-it can be confidently declared that this LMS can be used as a reliable learning facilitator. However, the Ministry's choice to install the Blackboard instead, remains more justifiable providing that a firewall system is mounted to enable us to step up to a more sophisticated and updated use of e-learning at the college in collaboration with New Zeeland Universities. A deep analysis of the merits and applicability of each LMS suggested is, nevertheless, more advantageous with the use of SWOT thinking technique. Apart from the weaknesses it could generate, the strengths seem to be leading to new horizons.

\section{REFERENCES}

1. Bechir Gattoufi \& Sultan Al-Adawi Significant Steps towards Information Technology development. A case Study: Intranet and Internet services in Nizwa College of Education. International Conference on Service Industry: Challenges and Opportunities; September13-14, 2006 at WALJAT University, Muscat Sultanate of Oman. http://www.waljatcolleges.edu.om/conference/1.htm

2. Said Al-Gattoufi \& Bechir Gattoufi How Learning Management System (LMS) can be used as a learning facilitator. Case study: Moodle at Nizwa College. International Conference on Computing \& e-Systems organized by TIGERA-USA, in Hammamet Beach, Tunisia, March 12-14 2007. (http://www.tigera.com)

3. Rich Internet application (RIA); http://en.wikipedia.org/wiki/Rich_Internet_application

4. Dr Jay Dempster, Centre for Academic Practice Undertaking a needs analysis for e-learning Email: jay.dempster@warwick.ac.uk

5. $\quad$ Gilb, T. and Finzi, S. (1988) Principles of Software Engineering, Addison Wesley.

6. Blackboard website

7. Moodle website 
Journal of College Teaching \& Learning - November 2007

Volume 4, Number 11 NOTES 